\title{
The prevalence of glaucoma
}

\author{
BO BENGTSSON \\ From the Department of Experimental Ophthalmology, University Eye Clinic, \\ and the Dalby Community Care Research Centre, Lund, Sweden
}

SUMMARY The occurrence of glaucoma was studied in a population comprising 1963 persons born during 1907 to 1921 and living in a small Swedish suburban and rural district. The records of 24 patients treated for glaucoma were examined. An estimate of the prevalence of glaucoma in untreated persons was based on an examination of 1511 subjects by standardised methods (including automatic perimetry) and strict diagnostic criteria. About $20 \%$ of all cases of glaucoma with visual field defects in the whole population were already known. Only 7 out of 15 cases of previously unknown but manifest glaucoma had intraocular pressures above $20.5 \mathrm{mmHg}$. The reduction in visual capacity caused by glaucoma in the present population was limited.

'To be acceptable, estimates of the prevalence of glaucoma should be based on an examination of all-or a truly representative sample-of a population of known composition, using standardized methods and diagnostic criteria. The initial definition of the disease depends above all upon the presence of a functional defect, detectable and repeatable on perimetry, consistent with glaucoma, and unexplainable on the grounds of other ocular pathology. The ideal method of identifying the glaucomatous members of a population is to screen the field of vision of each eye by a method sufficiently sensitive to detect all unequivocal glaucomatous change'. ${ }^{1}$ The Swedish registration system and the automatic perimeter ${ }^{2-4}$ have facilitated a study answering to the description above and resulting in the report below.

\section{Material and methods}

All persons born during 1907-21 and resident in the district serviced by the Dalby Community Care Centre were listed in December 1976. The list was arranged according to the residential addresses and kept up to date by means of weekly reports from the authorities on removals and deaths. In accordance with this list all inhabitants not known to be blind or on antiglaucomatous therapy were contacted in rotation during 1977 and 1978 and offered repeated ophthalmological examinations.

Correspondence to Med.lic. Bo Bengtsson, Dalby Community Care Research Centre, S-240 10 Dalby, Sweden.
Table 1 Numbers of persons, invited and examined, by sex and birth year

\begin{tabular}{llllll}
\hline \multirow{2}{*}{$\begin{array}{l}\text { Birth } \\
\text { year }\end{array}$} & Men & \multicolumn{3}{l}{ Women } \\
\cline { 2 - 3 } \cline { 5 - 6 } \cline { 5 - 5 } & Invited & Examined & Invited & Examined \\
\hline $1907-11$ & 314 & 234 & 335 & 245 \\
$1912-16$ & 341 & 281 & 290 & 238 \\
$1917-21$ & 330 & 248 & 328 & 265 \\
Total & 985 & 763 & 953 & 748 \\
\hline
\end{tabular}

Attempts at persuasion were avoided and only persons able and willing to attend within a few weeks were included in the survey.

Out of 1963 listed persons one had a bilateral leucoma, 24 were on antiglaucomatous therapy, 1938 were invited, and $1511(77 \%)$ were examined. The rate of attendance was largely independent of age and sex (Table 1).

\section{INQUIRY INTO THE RECORDS OF}

TREATED CASES

Out of 24 patients known at the local centre to be on antiglaucomatous therapy at the time of survey 4 were treated by the author and the remaining 20 at the respective eye clinic. Thus the computerised appointing system of the regional hospital could be used for an independent cross-check of the completeness of our information. The fact that the very same 20 clinical cases were brought out both ways seemed reassuring enough.

According to the records all treated patients had recently been subjected to visual field screening by 
static perimetry. It was therefore possible to establish the number of treated cases of manifest glaucoma within the district at the time of the survey. The records also provided adequate information on the visual acuity.

\section{DETECTION OF UNTREATED CASES}

(THE 'SURVEY')

Determination of the visual acuity, automatic perimetry, fundus photography, indirect ophthalmoscopy, slit-lamp examination and Goldmann tonometry were attempted on every person that took part in the survey. A detailed description of automatic perimetry-as applied in the present study-has been given elsewhere. ${ }^{5}$

\section{DEFINITION OF GLAUCOMA}

In the present paper a person is considered to be suffering from a manifest glaucoma when he has (1) a repeatable visual field defect consistent with glaucoma but not explainable on other grounds; and in the same eye (2) a glaucomatous cupping of the optic disc.

The use of a certain pressure level to distinguish chronic simple glaucoma from low-tension glaucoma has no basis in scientific fact. As pointed out by Drance et al.,6 it seems absurd to have to think of 2 separate diseases occurring in 1 patient just because a single intraocular pressure reading in one of the two eyes happens to exceed an arbitrary limit. It was therefore decided not to distinguish between different types of chronic glaucoma in persons with normal anterior segments. In the present report all such glaucomas have been called simple glaucomas (glaucoma simplex).

\section{Results}

The occurrence of glaucoma in the present study is summarised in Table 2.

Twelve persons with ocular hypertension, 1 with pseudoexfolations and 1 with goniodysgenesis, were treated to prevent an anticipated glaucoma, but much to our surprise not a single case of manifest chronic primary glaucoma was known in the present population.

The treated group contained 5 cases of manifest glaucoma-1 congenital and 4 secondary. Three of those 5 patients $(1$ with sclerokeratitis and 2 with central vein occlusion) were blind in one eye.

Automatic perimetry was completed in 2978 eyes of 1505 out of the 1511 persons who took part in the survey. The visual field screening was negative in 2887 eyes and positive in $91(3 \%)$. Seventy positive screenings were explained on 'nonglaucomatous' grounds. One unexplained positive was
Table 2 Occurrence of glaucoma among persons born 1907-21 and living in the Dalby district 1977-8

\begin{tabular}{|c|c|c|c|c|}
\hline \multirow[b]{3}{*}{ Type of glaucoma } & \multicolumn{3}{|c|}{ Numbers of cases } & \multirow{3}{*}{$\begin{array}{l}\text { Prevalence } \\
\text { of } \\
\text { manifest } \\
\text { glaucoma } \\
\text { (per cent) }\end{array}$} \\
\hline & \multicolumn{2}{|c|}{$\begin{array}{l}\text { Treated } \\
\text { among } 1963 \\
\text { listed }\end{array}$} & \multirow{2}{*}{$\begin{array}{l}\text { Detected } \\
\text { among } 1511 \\
\text { examined }\end{array}$} & \\
\hline & Latent & Manifest & & \\
\hline 1 A Chronic simple & 12 & - & 13 & 0.86 \\
\hline 1 B Capsular & 1 & - & 1 & 0.07 \\
\hline $1 \mathrm{C}$ Goniodysgenetic & 1 & - & - & - \\
\hline 1 Chronic primary & 14 & - & 14 & 0.93 \\
\hline 2 Angle closure & 2 & - & - & - \\
\hline Congenital & - & 1 & - & 0.05 \\
\hline \multirow{2}{*}{ Total } & 3 & 4 & 1 & $0 \cdot 27$ \\
\hline & 19 & 5 & 15 & $1 \cdot 25$ \\
\hline
\end{tabular}

false, 1 defect disappeared within a year, and 1 turned out to be part of a homonymous defect. The remaining 18 positives (in 15 cases) were caused by circumscribed or arcuate paracentral scotomata, consistent with glaucoma and not explainable on other grounds. They were all reproduced and also verified by Goldmann perimetry. They were found in eyes with glaucomatous cupping of the optic disc. Their extension was in general adequately mapped out by the 'automatic' field chart and in good agreement with the appearance of the optic disc.

Six subjects had lost one eye. In 38 eyes automatic perimetry was not completed and the possibility of a glaucoma had to be excluded on other grounds.

Fourteen cases of previously unknown manifest chronic primary glaucoma (13 simple and 1 capsular) were detected among 1511 subjects surveyed. Two of these 14 patients reported eye symptoms caused by a nuclear cataract and by a vertical squint, and 1 had reduced visual acuity caused by the cataract mentioned above.

No acute or congenital glaucomas had escaped discovery, and only 1 case of manifest secondary glaucoma was detected in the survey.

The prevalence of manifest glaucoma rose steeply with age (Fig. 1). There was only 1 man with simple glaucoma but in contrast only 1 woman with secondary glaucoma. The sex composition of the whole material of manifest glaucoma (6 men and 14 women) was less remarkable.

\section{Discussion}

In the present study no attempt was made to persuade the residents to take part in the survey. The rate of nonattendance was therefore not very low, but it may be hoped it was not much dependent 
Prevalence（per cent）

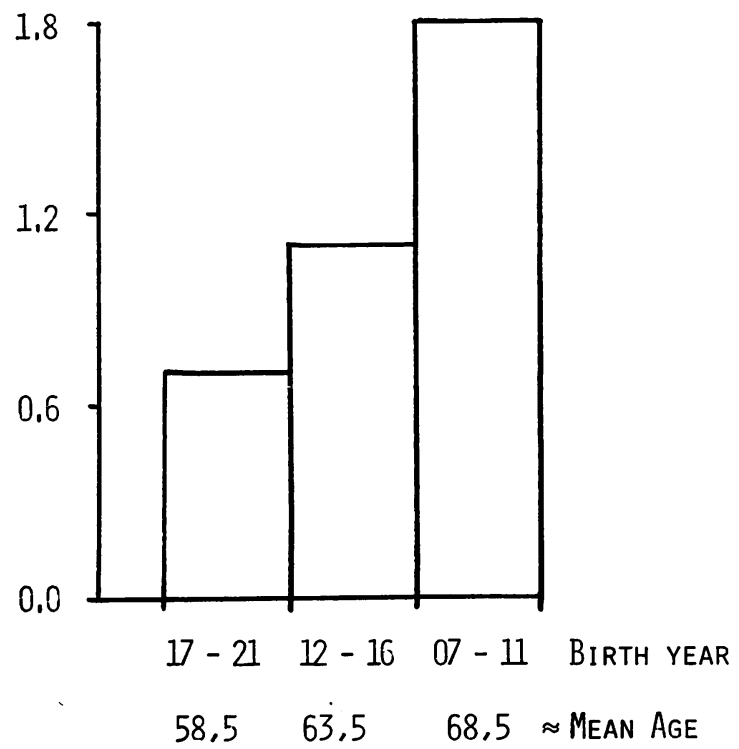

Fig. 1 Increase in prevalence of manifest glaucoma with age.

on fear of glaucoma inspired by the survey itself. The rate of visits to the regional eye clinic demanded by persons belonging to the present population was found to be totally unaffected by the survey. It was also the same in examined and not examined persons. There was therefore in our opinion no reason to assume that the prevalence of glaucoma in the survey was different from that in the whole population.

Estimates of the prevalence of glaucoma vary widely-largely owing to the lack of agreement on how to define the disease. The present estimate should be compared to that published by Hollows and Graham.?

Our estimate of the prevalence of manifest chronic simple glaucoma $(0.86 \%)$ is almost exactly the same as that of Hollows and Graham $70.83 \%)$ in the pertinent age groups (55-69 years). Although the number of persons with angle-closure glaucoma (latent or manifest) and congenital glaucoma was small in both studies, the agreement between Ferndale $(0.09+0.06 \%)$ and Dalby $(0 \cdot 10+0.05 \%)$ was excellent. The figures for secondary glaucomas are also very similar (0.26 and $0.27 \%)$, but they are not directly comparable owing to a lack of information on visual field defects in this section of the Welsh report.

Hollows and Graham ${ }^{7}$ reported that $30 \%$ of persons with manifest glaucoma simplex were under medical care but that only 7 out of 14 cases of previously unknown chronic simple glaucoma had intraocular pressures over $20.5 \mathrm{mmHg}$ at the initial examination. In our population 13 cases of manifest glaucoma simplex had all remained unknown up to the survey, and only 5 of them had intraocular pressures over $20.5 \mathrm{mmHg}$ at that time. The significance of these findings in relation to the value of current methods for early detection of glaucoma is so great that the present confirmation of the Welsh report seems long overdue.

Secondary glaucomas accompanied ocular disorders giving rise to other symptoms obvious to the patient as well as to the ophthalmologist. According to the records tonometry was in no case indispensable for the detection of glaucomas other than the latent chronic primary ones.

Our data suggest that new cases of manifest glaucoma occur at the same rate from the early 50 s on. The estimated incidence was $0.1 \%$, which means that, on an average, 1 new case can be expected every year among 1000 persons aged 55 to 70 years.

The gratifying fact that not a single case of bilateral blindness caused by glaucoma was found in the present population should be stressed. Blindness in one eye was rare and associated with types of glaucoma not likely to affect both eyes to the same extent. The dreaded and allegedly widespread disease 'chronic primary glaucoma' had caused 17 small field defects but no subjective symptoms at all.

This favourable state of health seemed to be largely independent of the efforts of the medical profession. In cases of secondary glaucoma most affected eyes were seriously damaged in spite of all therapy. Fourteen cases of latent chronic primary glaucoma were subjected to antiglaucomatous treatment, whereas the same number of cases of manifest chronic primary glaucoma remained untreated right up to the survey. Believing that lowering of the intraocular pressure may not prevent the development of manifest glaucoma, ${ }^{89}$ and knowing that our ability to predict the particular eyes in which glaucomatous visual field defects will occur is disappointingly low, ${ }^{10}$ we venture to assume that the therapy for simple glaucoma was misdirected in the present population. Anyhow, the treatment of 12 out of more than 100 persons with ocular hypertension could hardly have affected the incidence of manifest chronic simple glaucoma in the present population to any appreciable extent.

In the present population treated glaucomas were in many respects quite different from those detected in the course of the survey. Thus glaucoma, like 
many other diseases, presents a spectrum comprising various types of cases of the disease. Therefore clinical experience derived from the observation of self-selected ophthalmic patients with glaucoma cannot simply be extrapolated to cases of glaucoma more actively sought out and detected, for example, by automatic perimetry. Not only the characteristics but also the causes, the prognosis, and the susceptibility to treatment of glaucoma will have to be reassessed as a consequence of approaching changes in the clinical spectrum of the disease.

\section{References}

${ }^{1}$ Graham P. In: Heilmann K, Richardson KT, eds. Glaucoma Conceptions of a Disease. Stuttgart: Thieme, 1978; 7-17.

${ }^{2}$ Heijl A, Krakau CET. An automatic static perimeter: design and pilot study. Acta Ophthalmol (Kbh) 1975; 53: 293-310.
${ }^{3}$ Heijl A, Krakau CET. An automatic perimeter for glaucoma visual field screening and control: construction and clinical cases. Albrecht von Graefes Arch Klin Ophthalmol 1975; 197: 13-23.

${ }^{4} \mathrm{Krakau}$ CET. Aspects on the design of an automatic perimeter. Acta Ophthalmol (Kbh) 1978; 56: 389-405.

${ }^{5}$ Bengtsson B, Krakau CET. Automatic perimetry in a population survey. Acta Ophthalmol (Kbh) 1979;57:929-37.

-Drance SM, Sweeney VP, Morgan RW, Feldman F. Studies of factors involved in the production of low tension glaucoma. Arch Ophthalmol 1973; 89: 457-465.

${ }^{7}$ Hollows FC, Graham PA. Intraocular pressure, glaucoma, and glaucoma suspects in a defined population. $\mathrm{Br} J$ Ophthalmol 1966; 50: 570-586.

${ }^{8}$ David R, Livingston DG, Luntz MH. Ocular hypertension - a long-term follow-up of treated and untreated patients. Br J Ophthalmol 1977; 61 : 668-674.

${ }^{9}$ Nellemann SP, Nielsen NV, Nørskov K. Ocular hypertension: a 15-year follow-up. Acta Ophthalmol (Kbh) 1978; 56: 363-372.

${ }^{10}$ Armaly MF. Biostatistical analysis of the collaborative glaucoma study. Final report on contract No 1-EY-4-2167, 1977. 